\title{
Modelos gallego-portugueses de uso retórico: la personificación de los ojos en la escuela castellana*
}

\author{
Galician-Portuguese models of a rhetorical use: the personification \\ of the eyes in Castilian medieval poetry
}

\author{
María Isabel Toro Pascua \\ Universidad de Salamanca \\ mtoro@usal.es \\ ORCID iD: https://orcid.org/0000-0002-4323-3803 \\ Gema Vallín \\ Universidade da Coruña \\ g.vallin@udc.es \\ ORCID iD: https://orcid.org/0000-0001-8563-0076
}

RESUMEN: Si bien la referencia a los ojos como los culpables de la cuita amorosa formaba parte de la inventio poética desde las primeras escuelas líricas de la Romania, serán algunos trovadores de la gallego-portuguesa quienes la conviertan en parte esencial de la elocutio merced a la personificación. Este mismo uso retórico lo encontramos en la poesía de cancionero castellana desde sus orígenes: aparece ya en las cantigas gallegocastellanas de Villasandino, quien parece aceptarlo como rasgo identificativo de esta lírica, y en otras composiciones escritas en esta misma lengua híbrida. El uso elocutivo de la personificación de los ojos avala la consideración del corpus gallego castellano como enlace entre la lírica gallego-portuguesa y la castellana.

Palabras clave: retórica, lírica gallego-portuguesa, poesía cancioneril castellana, corpus gallego-castellano, círculos poéticos, tópica amorosa, personificación de los ojos.

ABSTRACT: Although the reference to the eyes as the perpetrators of the cuita amorosa was an asset of the poetic inventio from the first Roman lyrics schools, it was some Galician-Portuguese troubadours who made it an essential part of the elocutio through their personification. The same pattern can be found in several 15th century Castilian poets:

* Este trabajo se ha elaborado en el marco del proyecto OLíriCas, "El origen de la lírica castellana desde las fuentes gallego-portuguesas" (referencia PID2019-104393GB-I00 / AEI / 10.13039/501100011033), financiado por el Ministerio de Ciencia e Innovación.

Copyright: (9)2021 CSIC. Este es un artículo de acceso abierto distribuido bajo los términos de la licencia de uso y distribución Creative Commons Reconocimiento 4.0 Internacional (CC BY 4.0). 
the device already appears in the Galician-Castilian cantigas of Villasandino, who seems to consider it as one of the identifying features of the first Castilian written poetry and in some compositions of the Galician-Castilian corpus. The eloquent use of the personification of the eyes supports this new consideration of the Galician-Castilian cantigas.

Keywords: rhetoric, Galician-Portuguese lyric, Castilian songbook poetry, GalicianCastilian corpus, poetic circles, love topics, personification of the eyes.

Recordar que el motivo de la contemplación de la hermosura de la dama como origen del amor es probablemente uno de los tópicos más repetidos en la lírica culta de la Romania es, sin duda, aludir a una obviedad de sobra conocida. Siguiendo la costumbre de la poesía erótica latina, en particular de Ovidio, en el contexto de la casuística amorosa que vertebra el canto cortés desde sus mismos orígenes en la Provenza, la mirada es el desencadenante de todo el proceso erotológico que recrea líricamente la cansó: los ojos y todo el campo semántico relacionado con ellos se convierten desde un principio en elementos fundamentales en el desarrollo de la materia poética como parte fundamental de la inventio del poema, esto es, como parte esencial en la construcción de la complicada urdimbre tópica de la llamada "fin'amor".

Como cabía esperar, este motivo de valor nuclear en la casuística amorosa conocerá en su amplio recorrido diversas formas expresivas que, en el cancionero castellano del siglo XV, se explotarán profusamente como uno de los elementos más fértiles para la recreación del viejo concepto del amor. Intentar recuperar los diversos usos de este tópico es tarea ardua, pero basta una rápida mirada a unos cuantos cancioneros del periodo o a la obra de algunos de los más conspicuos poetas para espigar aquí y allá ejemplos significativos que dan muestra clara de las posibilidades que ofrecía para poetizar distintos contenidos dentro del amplio código cortés. Así, Juan de Torres recurrirá a este motivo en más de una ocasión, llegando incluso a utilizarlo como punto de partida para el juego retórico ${ }^{1}$; en una de sus composiciones transmitida en el Cancionero de Palacio (SA7, ID2591) la vista y el deseo se conjugan una vez más para exhibir la pericia del poeta ${ }^{3}$ :

Si mis tristes oxos veen

ante sí lo que dessean,

faç, Amor, que non desseen

lo que nunca jamás vean (vv.1-4) ${ }^{4}$.

\footnotetext{
1 En relación al tratamiento que Juan de Torres hace en su obra de los aspectos relacionados con el campo visual, aunque desde una perspectiva diferente a la que aquí tratamos, véase Haywood (2016).

2 Identificamos los cancioneros y los poemas castellanos siguiendo el catálogo de Dutton (1990-1991).

3 Sobre el juego poético entre la vista y el deseo, de amplia fortuna tanto en la lírica culta como en la tradicional, véase el trabajo de Toro Pascua y Vallín (2006).

${ }^{4}$ Citamos la pieza por la edición de Mosquera Novoa (2016: 122-124).
} 
En un poema copiado unos folios después, Rodrigo de Torres también declarará - aunque él lo hará ante su dama y no ante el mismo Amor-, que la sola vista de la belleza desencadena el deseo (ID2672, vv. 1-4):

Quien de gana vos otea

e bien [mira] vuestro aseo

mucho sufre gran deseo,

señora, quien vos desea.

En este mismo cancionero, Gonzalo de Cuadros mostrará el "gran placer e alegría" (ID2515, v. 8) que el ver y, como no, el desear, le han proporcionado, mientras que, ya mediado el siglo y en un sentido muy distinto, Francisco de Villalpando ligará los ojos a la metáfora del cautiverio: "Libertat he posseído, / señora, fasta vos ver" (ID2605, vv. 5-6).

El Cancionero de Herberay des Essarts (LB2) nos ofrece ejemplos interesantes; el poema de Gregorio en el que se lamenta por no haber nacido ciego para evitar así la muerte que provoca la pasión: “¡O, quién sin ojos nasciera!” (ID2197, v 1), o la maldición inicial con que un anónimo autor dirige su lamento a la dama: "Malditos sean mis ojos / porque tan linda os vieron" (ID2176, vv. 1-2).

Los ejemplos en este sentido se multiplican: los encontramos en el Cancionero de Oñate-Castañeda (HH1), en el de la Bristish Library o de Rennert (LB1), en el Cancionero General, entre las composiciones de Tapia, o entre los versos de Cartagena, por citar alguno ${ }^{5}$. En todos ellos, como venimos viendo, el tópico forma parte de un relato amoroso más amplio que se obvia en el poema, de modo que su interpretación presupone el conocimiento previo de ese código. Sin embargo, en algunas ocasiones la composición no se limita a incluir este motivo —aislado del contexto completo del que forma parte- para incardinar en él argumentos, metáforas o motivos afines - pues no otra es su finalidad retórica- (el deseo doloroso, el cautiverio, la muerte en vida, la queja o el gozo, entre otros muchos), sino que se expone como elemento esencial dentro de la explicación teórica, aunque lírica, del proceso amoroso; de este modo, se conforma en materia poética fundamental, esto es, en contenido primario del discurso.

Quizá el caso más conocido sea el que nos ofrece Juan Rodríguez del Padrón en sus Siete gozos de amor (ID0192), obra que resulta ser, en suma, una "parodia de las cuatro etapas del amor cortés provenzal y, además, una parodia del tratado escolástico formal", como señaló en su día Martin S. Gilderman (1982: 661) ${ }^{6}$, pero probablemente donde mejor se ilustra este procedimiento es en las coplas

\footnotetext{
5 Véase Rodado Ruiz (2000a: 62-67), donde recoge varios ejemplos en los que el uso de este motivo sirve para la introducción de distintos argumentos a través de los cuales se desarrolla el concepto amoroso.

${ }^{6}$ El primero de los gozos no es otra cosa que el enamoramiento a través de la visión de la dama; véase la edición de Beltran (2001: 91-110).
} 
contra Fortuna escritas por Garci Sánchez de Badajoz, en las que, en una larga disputatio, el autor culpa a la voluble dama de su desastrada situación amorosa y le pide explicaciones por permitir tal sufrimiento (ID6826); ella, en su descargo, recordará al quejoso enamorado el proceso por el cual, desde la contemplación de la mujer amada, quedó del todo enajenado:

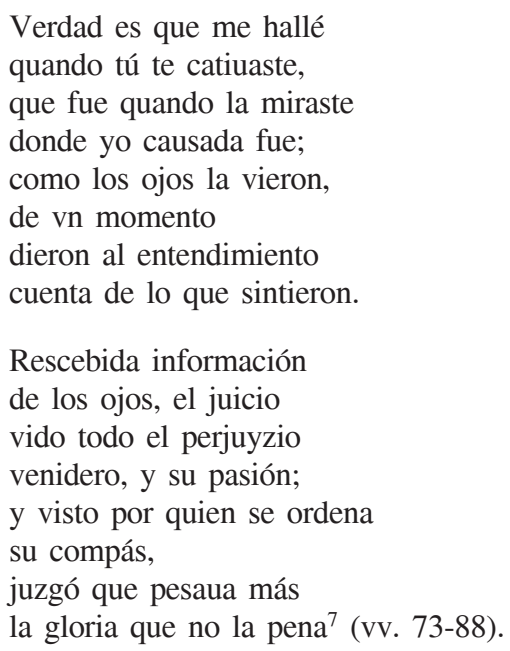

Rizando aún más el rizo, Jorge Manrique hará ambos usos del motivo en una misma composición: en su Escala de amor (ID6149), los ojos serán parte esencial en la explicación del proceso amoroso que, en este caso, se enriquece con la metáfora bélica para crear así, como explica Vicente Beltrán, "un juego de palabras basado en la aplicación del vocabulario militar a la relación amorosa y en la personificación de los sentidos y cualidades" (2000: 64).

En cualquier caso, en todos los ejemplos aducidos el motivo de los ojos forma parte, como ha quedado dicho, de la inventio del poema, de manera que sustenta la materia poética de la composición dentro del código amoroso. Pero, junto a estos, encontramos otros procedimientos a través de los cuales el tópico se introduce no ya como parte de la inventio o, cuando menos, no solo como parte de ella, sino también como elemento esencial de la elocutio: nos referimos a la personificación de los ojos. En estos casos no siempre funciona como simple ornatus integrado como una figura más en la urdimbre retórica, sino que en ocasiones se convierte incluso en el eje fundamental del poema sobre el que girarán otros recursos propios de esta poética.

Ya Pierre Le Gentil (1949: 71-79) ponía de manifiesto el gusto de la poesía peninsular del siglo $\mathrm{XV}$, y también de la francesa, por este tipo de

\footnotetext{
${ }^{7}$ Citamos por la edición de Gallagher (1968: 94-95).
} 
personificaciones, en particular por la del corazón y la de los ojos, algo que en el caso que nos ocupa resulta especialmente significativo en las producciones de la segunda mitad de la centuria. Como bien es sabido, el gusto por los géneros breves y la búsqueda de la sutileza, y a veces del exceso, en la expresión - lo único, por cierto, que pareció interesar a Gracián- favorecían la creación de complicados artificios retóricos ${ }^{8}$. Tal y como indica Estela Pérez Bosch (2009: 239):

Los géneros breves presentan una innegable predilección por las personificaciones, que lo suelen ser de accidentes de la personalidad (deseo, cuidado, afición), partes del cuerpo (corazón, ojos, lengua), y, en menor medida, de objetos que el poeta suele elegir para el simbolismo, la anécdota o el juego retórico de que son susceptibles.

La personificación no implica necesariamente la presencia de un diálogo en estilo directo. El supuesto diálogo con el personaje personificado se limita en ocasiones a un simple monólogo con un destinatario explícito que sirve como apoyo al sujeto en la búsqueda de sí mismo.

De entre los varios ejemplos que podemos mencionar, es probablemente el poema ID6115 el que desarrolla con mayor complejidad este recurso; en él, Pedro de Cartagena utiliza la personificación de los ojos y del corazón tanto para la creación del asunto argumental, esto es, la materia poética, como para la elaboración de un entramado discursivo que se desarrolla a través del debate entre ambas partes del cuerpo; un debate que, como indica Ana Rodado (2000b: 113), se zanja con un axioma incuestionable: "los ojos miran, el corazón consiente, pero quien sufre es el poeta".

Esta es la conclusión a la que parecen llegar todas las composiciones que se hacen eco del motivo. Aunque en algunas ocasiones el poeta nos comunica la responsabilidad absoluta de los ojos en el sufrimiento amoroso, exonerándose él mismo de toda culpa —es lo que hace Juan del Encina en uno de sus villancicos (ID3817): "Paguen mis ojos, pues vieron / a quien más que a sí quisieron" —, lo más habitual es encontrar al enamorado dirigiéndose directamente a ellos, tanto para culparles de todo su mal como para convertirlos en confidentes. En este contexto, a finales de siglo encontramos una fórmula que se repite, apenas sin variaciones, en la pluma de varios poetas, particularmente en las composiciones musicales de resabio más popular convertidas ya en gala cortesana: en varios villancicos, el sufriente enamorado insta a sus ojos al llanto o, por el contrario, intenta convencerles para que contengan las lágrimas: “¿Para qué queréys llorar, / mis ojos tristes?” (ID6892), pregunta el Comendador Escrivá; "Llorad, ojos, noche y día” (ID6461), exhorta Rull; "No lloréys, ojos, pues vistes / lo que ver

\footnotetext{
${ }^{8}$ En torno al uso que Gracián hace de la poesía de cancionero, véase Toro Pascua (2009).
} 
no merecistes" (ID4865), escribe Pedro Manuel de Urrea; "No lloréys mis ojos tristes" (ID2883), canta Juan Fernández de Heredia.

Como vemos, las modalidades son diversas, pero, en cualquier caso, la personificación de los ojos — a veces ligada a la del corazón o al motivo de las lágrimas- parece responder al gusto por el preciosismo retórico que, a estas alturas del siglo, dominaba el panorama lírico castellano: al progresivo decaer del dezir alegórico, al triunfo de las formas breves, del conceptismo y del acomodamiento de la poesía tradicional se unía, especialmente a partir de la segunda mitad del XV, la aclimatación más o menos feliz de algunos recursos petrarquistas. De hecho, el motivo del que venimos hablando no es en absoluto ajeno a la obra de los poetas sicilianos, de los stilnovisti ni, por supuesto, a la de Petrarca ${ }^{9}$, y claro es que la constatación del petrarquismo en algunos versos castellanos del momento parece poco discutible ${ }^{10}$.

Aunque en este caso la hipótesis resultara atractiva, lo cierto es que, como a Rafael Lapesa, no se nos escapa que "de las muchas coincidencias entre la poesía castellana y Petrarca hay que descartar las muchas originadas por el común fondo trovadoresco", que se reinterpreta a la luz de las distintas escuelas; si bien es verdad que, "con todo, es innegable que, ya fuese por evolución espontánea, ya por infiltraciones claras e imperceptibles, se formó en la lírica de Castilla un clima poético afín al petrarquista" (1982: 147) ${ }^{11}$.

No cabe duda de que el prolijo uso de esta figura viene motivado por la tendencia al virtuosismo, alimentado en parte por ese clima afín al petrarquismo del que hablaba Lapesa, pero debemos volver la vista a la corte castellana de Juan II para encontrar las primeras personificaciones de los ojos en la poesía castellana.

El motivo aparece, al menos, en tres composiciones de Juan de Torres: la ya citada ID0438 y las piezas ID2591 e ID2592. El dato es importante a la luz de las noticias aportadas por Lucía Mosquera en torno a los círculos en los que se difundieron sus obras (2015: 59-60); según esta investigadora,

circularon, sobre todo, en un entorno relacionado con Álvaro de Luna y Juan II de Castilla durante la primera mitad del XV: el hecho de que parte importante de sus textos se copien en vecindad con obra de poetas pertenecientes a la corte del privado así lo indicaría. Sin embargo, la compilación de otros poemas suyos en cancioneros de la corte de Navarra o incluso de la de Nápoles

\footnotetext{
9 Recuérdese, por ejemplo, el célebre soneto de Giacomo da Lentini Amore è uno desio che ven da' core, o la composición de Petrarca en la que leemos: "Occhi miei lassi, mentre ch'io vi giro / nel bel viso di quella che v'aà morti” Cortines (1984: XIV, 156).

10 Véanse los clásicos trabajos de Farinelli (1929), Fucilla (1953) y, muy especialmente, los de Rico (1976, 1978, 1987). Más recientemente se ha ocupado de este asunto Whetnall (2006) y Recio (2007) ha coordinado una importante monografía sobre el tema.

11 Es interesante a este respecto el capítulo que Rovira dedica a "La tradición italiana” (1990: 89-103).
} 
nos informa también de que ciertas composiciones interesaron y trascendieron lo suficiente como hallar cabida en otros ambientes y en época más tardía; es posible, incluso, que el propio poeta frecuentase esos entornos, sobre todo si consideramos que en aquel período los hombres relacionados con la corte con frecuencia llevaban una vida itinerante.

Más interesante, sin embargo, resulta comprobar que el tema de la vista y los ojos había sido utilizado antes por Alfonso Álvarez de Villasandino en algunas de sus cantigas gallego-castellanas. Como bien es sabido, este corpus intenta certificar la validez de la nueva escuela dotándola de unos caracteres que permitieran enlazarla directamente con la otra escuela de Castilla, la gallego-portuguesa ${ }^{12}$. Villasandino, el "maestro e patrón" de la poesía en castellano, tal y como lo califica Baena en su prólogo, es el que marca esa transición hibridando la lengua y retomando algunos de los motivos esenciales del lirismo gallego (Toro Pascua y Vallín, 2005) ${ }^{13}$.

Respecto al que nos ocupa, se ha de subrayar que no se puede establecer parangón posible con otras escuelas poéticas en cuanto al desarrollo y los logros artísticos que alcanzó en el temprano lirismo peninsular, tanto en las cantigas de amor como en las de amigo. Contemplándolas en su conjunto, bien pareciera que el topos de la personificación de los ojos hubiera surgido de la misma inventio poética gallego-portuguesa. Las cifras así lo constatan, pues, como observa José António Souto Cabo en el estudio que realizó sobre el uso que de él hacen sus autores, son ni más ni menos que ciento veinticuatro las composiciones en donde el tema alcanza gran "multiplicidade de posibi-

12 Huelga decir que la lengua gallego-portuguesa es la propia, también, de la poesía lírica producida en Portugal; aquí, sin embargo, nos interesa poner de manifiesto la consideración de esta lírica como algo identitario de las cortes castellanas hasta la primera mitad del siglo XIV; precisamente la situación de los reinos portugués y castellano mediado el siglo y la entronización de los Trastámara serán circunstancias que expliquen, en parte, la sustitución de esta lengua poética por la castellana para las producciones líricas de Castilla, si bien la recurrencia explícita a la tradición gallego-portuguesa, e incluso a la lengua, será necesaria para dar carta de naturaleza a estas composiciones. Véase Toro Pascua y Vallín (2005). Sobre la producción poética peninsular en este periodo, tanto en gallego-portugués como en castellano, véanse Deyermond (1982) y Tavani (1983).

13 Lapesa (1953-1954) atribuyó la hibridación lingüística que caracteriza las cantigas de Villasandino a la incompetencia lingüística de los poetas y a la intervención de los copistas; sin embargo, estudios más recientes — sin negar que esta deturpación sin duda existe en algunos casosargumentan que la hibridación está ya en el origen de las composiciones de Villasandino y de los autores del llamado corpus gallego-castellano - que muestran conocer bien la tradición gallegoportuguesa-, como rasgo característico de la evolución de la tradición lírica peninsular. Además del trabajo ya citado en el texto, véanse, entre otros, los de Zinato (1996), Casas Rigall (2009), Proia (2015), Pla Colomer (2016) y Sáez Durán (2019); también autores como Lorenzo Gradín (1997a: 53-54), Beltrán (2009: 39-44) y Pérez Priego (2013: 20), en sus trabajos dedicados a la historia de la literatura, consideran el uso de esta lengua híbrida por parte de Villasandino y de otros poetas una característica de la primera poesía de cancionero castellana, que, en palabras de la primera, recurre al uso de un "código mixto". 
lidades"; al mismo tiempo, subraya que aquellas en donde los ojos aparecen tratados como un "ente autónomo" son las cantigas que revisten mayor interés expresivo y retórico (1988: 403).

De hecho, estas últimas, que pertenecen a épocas y gustos diferentes, fueron confeccionadas en su mayor parte por trovadores sobresalientes, que crearon ciclos temáticos en torno al tema de la vista y los ojos. Es el caso, por ejemplo, de Pai Soarez de Taveirós, quien en Meus ollos, quer vus Deus fazer presenta una realidad tan tangible como inusual en el género de la cantiga de amor, pues los ojos sufren "Ca vos faran cedo ver / a por que eu moiro, casar", advierte el enamorado (Vallín, 1996: 179, vv-7-8). Este infortunio afectivo reaparece en la cantiga que viene copiada a continuación en los dos cancioneros que la trasmiten —Como morreu quen nunca ben (A 35, B 150)—, si bien aquí no se desarrolla mediante el motivo de la personificación de los ojos, sino por medio de otro igualmente frecuente en la escuela como es el de la muerte por amor: "e quen a viu levar a quen / a non valia, nen a val" (Vallín, 1996: 189, vv. 18-19). Quizá esté relacionada con ambas A ren do mundo que mellor quería, si entendemos que los versos del estribillo — "Sennor, sennor, agora vi / de vus quant' eu senpre temi!"- reflejan que el abandono por el amante preferido era temido y esperado por el trovador (Vallín, 1996: 159, vv. 5-6).

Menor duda suscita el hecho de que el colofón a toda la triste historia lo pongan los versos copiados en último lugar en la sección que ocupan las cantigas de amor de Pai Soarez dentro del Cancioneiro da Ajuda (A 39), siendo además el único que los ha conservado. Aunque quizá se trate de la primera estrofa de un texto que no llegó a copiarse entero, esta estrofa, como bien observó Valeria Bertolucci, "si può considerare una breve cobla galante, congegnata come un' artificiosa variazione sul motivo degli occhi” (1963: 65). Como puede verse, son suficientes seis versos para dar una última vuelta de tuerca a la situación, y ofrecer otra perspectiva del motivo que nos ocupa (Vallín, 1996: 241):

\footnotetext{
Meus ollos, gran cuita d' amor me dades vós, que sempr' assi chorades; mais ja des aqui, meus ollos, por Nostro Sennor, non choredes, que vejades a dona por que chorades.
}

Tomemos asimismo, a título de ilustración, dos cantigas de Joan Soarez Coelho, en concreto Pelos meus olhos ouv' eu muito mal y Non me soub' eu dos meus olhos melhor. Fueron copiadas una a continuación de la otra en el antiguo códice de Ajuda (A 163-164) y en el Cancioneiro da Biblioteca Nacional de Lisboa (B 316-317) porque también configuran un breve ciclo temático en 
torno a los ojos y la vista. Así, mientras en la primera el trovador no quisiera tener ojos con que ver a su "senhor", pues "muito mal / e pesar tant', e tan pouco prazer" le procuran (Vasconcelos, 1990: 327, vv. 1-2), en la segunda toma una decisión drástica y se venga de ellos matándolos, aunque a la postre sea una mala solución (Vasconcelos, 1990: 328, vv. 1-6):
Non me soub' eu dos meus olhos melhor per nulha ren vingar ca me vinguei.
E direi-vus que mal que os matei:
levei-os d' u veian sa senhor.
E fiz seu mal e do meu coraçon
por me vengar d' eles, e por al non!

Si este trovador portugués encuentra un planteamiento brillante para subrayar el protagonismo que la vista y los ojos tienen en la cuita amorosa, hasta el punto de ser imitado en dichos términos por trovadores ajenos a su escuela, como parece ser el caso del catalán Cerverí de Girona (Cabré, 2011: 116), quien en verdad convierte en materia de primer orden el asunto es Joan Garcia de Guilhade. Suyo es el hallazgo de los famosos ojos verdes que luce la joven enamorada de Par Deus, amigas, que será?. Aquí es tan sorprendente la descripción física de la amiga — con "olhos verdes" y de "bon talho"- como relacionar la indiferencia del muchacho con el tópico del mundo al revés — “que será? /pois $<\mathrm{j}>\mathrm{a}$ o mundo non é ren / nen quer amig' a senhor ben, / e este mundo que ér ja"- (Cohen, 2003: 231, vv. 1-3). Como señala Giuseppe Sansone, quien estudia la técnica de sus cantigas, "Il tramite visivo è per lui non solo una realtà stabile, un riquiamo suasivo del vivere amoroso, ma anche forza generatrice di occasione lirica" (1974: 20). En efecto, Guilhade se emplea a fondo analizando el motivo desde diversas perspectivas. Baste citar los primeros versos de una de estas piezas del trovador portugués para darnos cuenta de su pericia retórica con el dobre para darle mayor vuelo al motivo ${ }^{14}$ :

$$
\begin{aligned}
& \text { U m' eu parti d' u m' eu parti, } \\
& \text { logu' eu parti aquestes meus } \\
& \text { olhos de veer, e, par Deus, } \\
& \text { quanto ben avia perdi; } \\
& \text { ca meu ben tod' era en veer, } \\
& \text { e mays vos ar quero dizer: } \\
& \text { pero vejo, nunca ar vi (vv. 1-7). }
\end{aligned}
$$

En fin, con una tradición tan dilatada y rica a sus espaldas, Villasandino no podía desaprovechar el caudal y acoplarlo a sus propias cantigas. Así, en

\footnotetext{
14 Véase el minucioso análisis retórico que realiza de este poema Sansone (1974: 33-35). Para el dobre, véase Cunha (1982: 201-218), Beltrán (1995: 190-200) y Lorenzo Gradín (1997b).
} 
[D]esque de vos me partí (ID1161) el enamorado expresa su temor porque los ojos, en connivencia con el corazón, no mueran "penando" la ausencia de la dama ${ }^{15}$ :
[D]esque de vos me partí, lume d'estos ollos meus, por la fe que devo a Deus jamás placer nunca vi; tan grandes coitas sofrí, sufro e atendo sufrer, que pois non vos posso ver non sé qué seja de mí.
Choram con grant soedade estos meus ollos cativos; mortos son, pero andan vivos mantenendo lealtade.
Señora, grant crueldade faredes en olvidar a quen non le plaz' mirar sinon vossa grant beldade.
Meus ollos andan mirando noite e día a todas partes, buscando por moitas artes cómo non moiran penando; mais meu coraçón pensando non les quere dar placer por vos sempre obedecer, e lo non çessan chorando.

La distancia retórica y formal que media entre las cantigas gallego-portuguesas y esta, obviamente, es manifiesta, pues, por ejemplo, mientras que la cantiga de amigo condensa las palabras y las ideas, en sintonía con el posterior villancico castellano, el modus operandi de Villasandino consiste en exponer a modo de cascada la idea que abre el poema, sirviéndose para ello de galas retóricas como el políptoton verbal ("tan graves cuitas sofrí, / sufro e atendo sufrer", vv. 5-6), el oxímoron ("estos meus ollos cativos; / mortos son, pero andan vivos", vv. 10-11) o la perífrasis ("Señora, grant crueldade / faredes en olvidar / a quen non le praz' mirar / sinon vossa grant beldade", vv. 13-16) ${ }^{16}$.

\footnotetext{
${ }^{15}$ Citamos los poemas de Villasandino por la edición de Brian Dutton y Joaquín González Cuenca (1993: 28).

${ }^{16}$ Para el estudio de la retórica en la poesía de cancionero castellana es fundamental el trabajo de Casas Rigall (1995).
} 
Con todo, vincular el llanto a la separación o a la partida del ser amado, como hace aquí, por muy tópico que nos parezca, es un modo de formular el motivo del que, sin embargo, solo se hacen eco un puñado de diez escogidas cantigas, compuestas todas por trovadores gallegos - la mayoría contemporáneos o relacionados entre sí-, de las cuales seis pertenecen al género de amigo y cuatro al de amor ${ }^{17}$. Constituyen, por tanto, un sugerente ejemplo para observar el poema castellano a la luz de su modelo de inspiración. Así, la primera de ellas bien puede ser A San Servand' en oraçon, donde su autor, Joan Servando, expone con claridad nuestro uso retórico tal y como lo plantea Villasandino. Basta con citar la estrofa primera para darse cuenta de este particular $^{18}$ :
A San Servand' en oraçon
foi meu amig' e, por que non
foi $\mathrm{e}<\mathrm{u}>$, choraron des enton
estes meus olhos con pesar
e non os poss' end' eu quitar
estes meus olhos de chorar

Este trovador desarrolla el tema por partida doble. En A San Servando foi meu amigo encontramos a la misma joven que llora la marcha del amigo, y que increpa a su madre porque no le permite acudir a su encuentro: "E por que me tẽedes guardada / direi o a Deus / e chorarei dos olhos meus" (Cohen, 2003: 72, vv. $6-8)^{19}$.

También originario de Galicia y contemporáneo suyo es Bernal de Bonaval, autor de otra de las cantigas de nuestro pequeño corpus ${ }^{20}$. Si bien resulta interesante

\footnotetext{
17 Para la consulta del corpus lírico profano nos hemos servido de la utilísima plataforma informática Littera (Lopes y Ferreira, 2011-); asimismo hemos tenido en cuenta las ediciones de Universo Cantigas (Ferreiro, 2018-), pese a estar en proceso de construcción - de aquí tomamos, no obstante, las soluciones gráficas que ofrece para los nombres de los trovadores-. En todo caso, siempre citamos los textos a partir de las ediciones críticas y anotadas que nos parecen mejores. Cuando citamos el texto por el íncipit lo identificamos siguiendo la numeración que trae Tavani (1967).

18 Seguimos la edición de Cohen (2003: 371).

19 La coherencia temática entre ambas cantigas se extiende a buena parte del cancionero de Joan Servando, marcado por un discurso cuyo tema principal gira en torno a las vicisitudes por las que ha de pasar la moza protagonista a causa de la peregrinación de su amigo a San Servando, lo que a menudo provoca su llanto. Todas las piezas parecen referir el santuario orensano de san Servando de Pazos, sito en la parroquia de santa María de Barxeles (Gonçalves 1986: 49-50). Para el estudio y análisis de las mismas remitimos a Burgazzi (2015: 9-43); en relación al género de romería se puede consultar entre otros estudios Brea (1999) y Correia (1993). Véase también el innovador trabajo sobre la estructura formal de las cantigas de Servando realizado por Cohen (2013). Respecto al papel de las mujeres en la peregrinación a los santuarios gallegos, puede consultarse Riquer (2015: 155-167).

${ }^{20}$ La actividad poética de Joan Servando "debe datar de meados ou do terceiro quartel do séc. XIII", dada "su inclução num cancioneiro dominado por jograis provenientes igualmente da Galiza", apunta Resende de Oliveira (1994: 370) —Liedersammlung que fue incorporada, junto con otros materiales, al antecedente del que derivan los apógrafos italianos $\mathrm{B}$ y $\mathrm{V}$ - . Aunque se trata de un
} 
leer su A Bonaval quer' eu, ma senhor, hir a la par que la pieza de Julião Bolseiro Non perdi eu, meu amigo, des que me de vós parti. Teniendo en cuenta que, como hemos dicho, en la escuela apenas llega a fraguar la idea de unir el llanto y la ausencia a la personificación de los ojos, el que ambos trovadores compongan su obra en el ámbito compostelano cuando estaba bajo el auspicio del arzobispo Joan Airas ${ }^{21}$, quizá tampoco sea casualidad que el íncipit de la pieza de Bolseiro aparezca, con leves variaciones, en el segundo verso del poema de Bonaval $-\mathrm{y}$ que nos remite, por cierto, a [D]esque de vos me partí de Villasandino-. Pero contrastemos ambos textos para ver otro nexo común. A Bolseiro le basta el dístico de base y un estribillo de dos versos para contar en dos estrofas que no son ni los ojos con su llanto ni el corazón con su coita los verdaderos afectados por la separación, pues lo que la joven lamenta al haberse alejado de su amigo es el tiempo que perdió no estando a su lado. Dicen así los versos ${ }^{22}$ :

Non perdi eu, meu amigo, des que me de vós parti, do meu coraçon gran coita nen gran pesar, mais perdi quanto tempo, meu amigo, vós non vivestes comigo

Non perderan os olhos meus chorar nunca, nen eu mal, des que vos vós daqui fostes, mais vedes que perdi al: quanto tempo, meu amigo, vós non vivestes comigo

Por su parte, Bernal de Bonaval introduce en el texto el motivo del insomnio amoroso, tan apreciado por Bolseiro ${ }^{23}$ :

arco temporal amplio, nos ayuda a limitarlo en las últimas décadas del siglo el hecho de que las diecisiete cantigas de amigo y las dos de amor que compuso se inserten junto a las dos de Bernal de Bonaval, sugiriendo la existencia de un conjunto coherente, esto es, el "cancioneiro" del que nos habla Resende de Oliveira, en el que se compilaría la obra de ambos junto a la de otros juglares gallegos: Bonaval le precede en las dos secciones en las que se insieren sus cantigas, aunque en origen era quien lo encabezaba, según se deduce de la rúbrica del Cancioneiro da Biblioteca Nacional de Lisboa ("En esta folha adeante se comenzam as cantigas d'amor. Primeiro trovador Bernal de Bonavalle"; cifra B fol. 225v). Las numerosas citas en ellas al templo dominico de Bonaval, del que toma su nombre, permiten suponer que sea el mismo "frater Bernardus, prior Bone Uallis" que aparece en el testamento de un juez compostelano fechado en 1279. Para Souto Cabo (2012: 279), editor del documento, a favor de esta identificación "depõe o tratamento de Dom que lhe concedem os outros poetas", pues siempre se dirigen a él como "Don Bernaldo".

${ }^{21} \mathrm{Si}$ el primero fue prior del templo de Bonaval, el segundo, Julião Bolseiro, parece que custodiaba las "bursas" donde se contenían las donaciones de los fieles a la catedral (cf. Souto Cabo 2012: 285).

22 Reproducimos el texto siguiendo la edición de Cohen (2003: 414).

${ }^{23} \mathrm{Si}$ bien el motivo en cuestión no es ajeno a los trovadores gallego-portugueses, lo cierto es que el referente indiscutible del mismo es este trovador. De las tres cantigas que dedicó a las noches insomnes, Reali (1964: 7), su editora, subraya la excepcionalidad que representan en el corpus de Bolseiro al advertir que "l'inspirazione poética sembrerebbe qui più vicina all' ambien- 

A Bonaval quer' eu, ma senhor, hir
e, des quand' eu ora de vós partir
os meus olhos, non dormirán.
Hir-m' ey, pero m’é grave de fazer,
e, des quand' eu ora de vós tolher
os meus olhos, non [dormiran].
Todavya ben será de probar
de m' ir; mays, des quand' eu de vós quitar
os meus olhos, non [dormiran].

Si la trayectoria vital de ambos nos induce a pensar que Bonaval y Bolseiro tuvieron que conocer sus respectivas obras, Joan Servando, a su vez, hubo de estar muy al quite de lo que componían Martin Padrozelos y Nuno Treez, o viceversa. Tanto Padrozelos en la cantiga de amigo Amigas, sejo cuidando, como Treez en Des quando vos fostes daqui, meu amigo, sen meu prazer (Cohen, 2003: 479 y 433 respectivamente) exponen la misma situación, aunque con menor imaginación retórica ${ }^{24}$.

Las cuatro cantigas de amor encaran el motivo desde la misma perspectiva aunque ninguna es de meestria, la forma estrófica mayoritaria de esta variedad -25 . Que doo que agora ei de Roi Fernandiz de Santiago (Airas Freixedo, 2010) y Par Deus, senhor, en gran coita serei de Nuno Fernandez Torneol (Vasconcelos, 1990: 155-156) repiten en el estribillo y en posición de rima los términos "partir" y "vir", en este mismo orden, pues es en él donde condensan la carga emotiva de la adversa situación amorosa que describen ${ }^{26}$. Así, mientras el primero citado dice "ca nunca os hei a partir / de chorar, u vos eu nom vir", Torneol a su vez escribe "pois eu de vós os meus olhos partir / e os vossos mui fremosos nom vir".

Al igual que los anteriores, ambos trovadores nos trasladan a Galicia, tanto a Santiago como a la provincia de Pontevedra. Contrastando la fecha del testamento que mandó redactar Rui Fernandes en $1273^{27}$ con la de 1244, año de una escritura

te delle kharge che alla sommessa temperie della lirica amorosa gallego-portoghese". Citamos la cantiga de Bonaval por la edición de Indini (1978: 124).

${ }^{24}$ Los dos son, como Servando, trovadores de santuario vinculados a parroquias pontevedresas, y también estuvieron activos en las mismas décadas del siglo XIII (Souto Cabo, 2018: 92-94 y 97-99).

${ }^{25}$ Mientras que el $92 \%$ del total de cantigas de amigo son de refram, solo la mitad de las de amor rematan con estribillo (Cf. Beltrán, 1993b: 139).

${ }^{26}$ Ambas tienen el esquema estrófico abbaCC y varias rimas en común (-ir en el estribillo, -ei y -er para la rima a, y -ar e -i para la rima b); están formadas por cuatro estrofas, pero la cantiga de Rui Fernandes lleva fiinda. Para estas y otras características métricas de los dos textos, remitimos a Tavani (1967: 190 y 170 respectivamente); la pieza de Torneol tiene ahí el número 160:182 y la de Rui Fernandes es la 160:382.

27 Véase la edición del documento en Airas Freixedo (2010: "O autor"), quien traza la biografía de este clérigo santiagués a partir de su vinculación con Salamanca, como profesor del estudio 
donde se documenta a un "Nuno Fernandi Torniol" 28 , podemos deducir que también sus respectivas carreras literarias se desarrollaron entre mediados y primeras décadas de la segunda mitad del XIII, y en la órbita cortesana de Fernando III ${ }^{29}$.

Las dos últimas cantigas del corpus pertenecen a Joan Vaasquiz de Talaveira y Meen Rodriguez Tenoiro. Leyendo en paralelo la primera estrofa de ambas reconocemos, más que la afinidad, el molde común. En estos términos se expresa Joan Vaasquiz (Fregonese, 2007: 136):

Parti-m' eu de vós, mha senhor, sen meu grado una vez aqui, en a terra hu eu vivi andey sempre tam sen sabor que nunca eu pudi ver de rem, hu vos non vi, prazer.

A su vez, Tenoiro comienza su poema del siguiente modo:

Quant' á, senhor, que m' eu quitei

de vos, tant' á que d' al prazer non vi; mais pois de vus veer [Deus] guisou, $j(a)$ agora verei prazer, por quanto pesar vi, des quando m'eu de vos parti,

Esta cantiga de amor presenta un grado mayor de elaboración con respecto a la de Talaveira y a las dos anteriores. Desde el punto de vista estrófico, destaca su complejidad al ser completamente atehuda, ya que liga los versos y las estrofas desde el principio hasta el final ${ }^{30}$. En cuanto a la retórica, los sentimientos extremos que confluyen por la separación y posterior reencuentro de los amantes se exponen mediante la contentio, alojando el estribillo el binomio "pesar" versus "prazer"

salmantino (ya advertida en su momento por Beltrán de Heredia, 1970: 85). Sobre su vida puede consultarse asimismo el trabajo de Ron Fernández (2005).

${ }^{28}$ Pertenece al monasterio pontevedrés de Poio y es muy plausible pensar que remita a nuestro autor, como indica el editor de la escritura Ron Fernández (2015: 302-305). Por las mismas fechas, un hermano del trovador ostentaba una propiedad en Córdoba, fruto de su participación en la reconquista de la ciudad llevada a cabo por Fernando III en 1236, según Beltrán (1997: 92). Otro posible hermano, Abril Fernandes "Turniol", clérigo compostelano, firma su testamento en 1269 (Souto Cabo, 2012: 282).

${ }^{29}$ Sobre la relación de ambos con esta corte, véase Souto Cabo (2018: 94-95). Entre las aportaciones culturales de Fernando III, destaca la de haber dotado de grandes recursos a la universidad salmantina, convirtiéndola en una de las más sobresalientes de Europa, tal y como han puesto de relieve autores como Richard (2011: 159); para el estudio de la historia de esta universidad es del todo fundamental el trabajo elaborado por varios especialistas bajo la dirección de Rodríguez-San Pedro Bezares (2002-2019).

${ }^{30}$ Esta forma de ligar todo el poema es considerada por la escuela gallega un mérito de estilo elevado. Véase su uso y características en Gonçalves (1993: 167-186) y en Beltrán (1993a: 70). 
como polos representativos de ambas situaciones: "já verei / prazer, por quanto pesar vi / des quando m' eu de vós parti”. Respecto al tema, está estrechamente vinculada con otra cantiga del trovador que asimismo es atehuda ata a finda, esto es Quando m' eu mui triste de mia senhor (Vasconcelos, 1990: 440-441) ${ }^{31}$.

Como vamos viendo, el ensamble de la temática de la vista y los ojos con la del corazón aparece a menudo en la cantiga gallego-portuguesa, donde presenta formulaciones que encontramos también en las cantigas gallego-castellanas de Villasandino y que se repetirán después en varias composiciones castellanas a lo largo de todo el siglo XV con no poca fortuna. En la otra pieza que dedica este poeta al tema, ;Ay, meus ollos, que quisistes (Dutton y González Cuenca, 1993: 30-31), se advierten muchas semejanzas expresivas y temáticas con la pieza Eya, senhor, aque-vos min aqui! (Finazzi-Agrò, 1979: 86), compuesta por el trovador tardío Joan Meendiz de Briteiros. Dice Villasandino en la segunda estrofa:

ollos tristes, vosso brío

faz' sofrer coita mortal

a meu coraçón leal,

que jamáis non atende ben,

por vos ir mirar a quen

non sabe ren de meu mal (vv. 14-19).

lo que Briteiros había expresado en los términos:

hu eu non possa poer estes meus

lhos nos vossos, de que tanto mal

me vem, senhor, e gran coita mortal

me vós destes eno coraçon meu (vv. 14-16).

Una vez más, esta cantiga de Briteiros despunta por la excelencia formal —es atauda - , así como por la imaginación temática: la dama aquí ha hecho llamar

31 Ambos se hubieron de relacionar en la corte del rey Sancho IV, pues Talaveira aparece en el libro de cuentas del rey por haber recibido 2000 maravedíes en compensación por haberle acompañado en su expedición a Bayona en 1286 (Gaibrois de Ballesteros, 1922: I, CLXXI), mientras que Tenoiro recibe una suma similar en 1290 como vasallo del monarca (Gaibrois de Ballesteros, 1922: I, LII-LIII); además, existen otras noticias indirectas que lo vinculan con Sancho IV (Beltrán, 1996: 134). Joan Vaasquiz también estuvo activo como trovador en la corte de Alfonso X, pues mantuvo relaciones literarias con tres trovadores pertenecientes a ella, como son Joan Airas de Santiago, Pero Amigo de Sevilla y el juglar Lourenço (Fregonese, 2007: 18-29). Meen Rodriguez aparece documentado en el reinado del rey Sabio desde la toma de Jerez, tras la cual recibe numerosos bienes (la repartición se lleva a cabo entre 1264 y 1269), hasta 1272 (Víñez, 1996: 539-540). De hecho, la escritura de dos tençoes junto con Joan Soarez Coelho (1235-1279) y Julião Bolseiro (1240) también lo sitúan en ese tiempo. Varios autores del entorno poético alfonsí tomaron parte en el famoso ciclo de las cantigas del ama de cría, iniciado por Coelho y en el que también participó Bolseiro (Beltrán, 1998). Este último entabló relación literaria con Meen Rodriguez Tenoiro, pues compusieron a medias una insultante tensó que nos hace suponer que entre ambos existía además una relación de confiada amistad; véase Julião, quero tigo fazer en Rodrígues Lapa (1965: 447-448). 
a su amante, pero cuando este llega a su lado y la mira a los ojos se comporta “como vay cervo lançad' a fugir". Villasandino, por su parte, desarrolla el motivo mediante una exposición ordenada de los hechos. Por no atreverse a declarar sus sentimientos a la dama desde que sus ojos se clavaron en ella, el enamorado padecerá todos los rigores de su timidez, tales como la muerte, la prisión o la crueldad de la mujer; aunque en un inesperado quiebro final, le pide a sus ojos: "a ésta mirade, / que por verdade / mellor non vi". De un autor a otro hemos pasado, pues, de la cobardía al coraje, a encontrarnos con dos posturas frente al motivo que por contrapuestas no dejan de ser complementarias. En fin, otro motivo común es el de "ver y desear" — "de mais aver esses olhos veer / e desejar o vosso ben" canta Briteiros, y "Çerto é que morte sento, / ollos, por vosso mirar / e non he consolamento / si non ver e dessejar", lamenta Villasandino-.

Las piezas trovadorescas traídas a colación guardan innegables semejanzas con las cantigas de Villasandino, pero solo porque pertenecen al gran caudal poético donde este autor encontró modelos para experimentar y renovar la tradición a la que pertenecía. Lo innegable, en todo caso, es que el poeta castellano compuso dos de sus cantigas gallego-castellanas, así como la estrofa final de Tempo ha que muito afané (Dutton y González Cuenca, 1993: 35) —también en lengua híbrida- en torno a un motivo que alcanzó soberana efervescencia en la escuela poética gallego-portuguesa como parte esencial de la configuración retórica de la canción, no únicamente como parte inevitable de la inventio en el tratamiento de la materia amorosa, ni siquiera como un motivo más de la elocutio.

En el ámbito peninsular, la personificación de los ojos adquiere un valor nuclear en el canto cortés, primero en gallego-portugués y después en castellano, algo que no observamos en otras escuelas trovadorescas. Villasandino encontrará en los trovadores gallegos el modelo para la recreación del mismo tópico, siguiendo una vez más su costumbre de recurrir a los usos más originales de la prestigiosa escuela para dar carta de naturaleza a la nueva lengua lírica (Toro Pascua y Vallín, 2005). La poesía castellana será feliz receptora de esta retórica de los ojos, que conocerá un amplio desarrollo a lo largo de todo el siglo XV, convirtiéndose en uno de los alardes propios del artificio expresivo que caracteriza al cancionero a finales de la centuria.

\section{BIBLIOGRAFÍA}

Airas Freixedo, Xosé Bieito (2010): O cancioneiro de Roi Fernandiz, clérigo de Santiago, Vigo, Universidade de Vigo, <http://locuscriticus.webs.uvigo.es/Roi/index.html>.

Beltrán, Vicente (1993a): “Atá fiinda”, en Giulia Lanciani y Giuseppe Tavani (coords.), Dicionário da literatura medieval galega e portuguesa, Lisboa, Caminho, pp. 70-71.

Beltrán, Vicente (1993b): "Cantiga de mestria”, en Giulia Lanciani y Giuseppe Tavani (coords.), Dicionário da literatura medieval galega e portuguesa, Lisboa, Caminho, p. 139. 
Beltrán, Vicente (1995): A cantiga de amor, Vigo, Galaxia.

Beltrán, Vicente (1996): "Tipos y temas trovadorescos XI. La corte poética de Sancho IV”, en Carlos Alvar y José Manuel Lucía Mejías (coords.), La literatura en la época de Sancho IV (Actas del Congreso Internacional "La literatura en la época de Sancho IV", Alcalá de Henares, 2124 de febrero de 1994), Alcalá de Henares, Universidad de Alcalá, pp. 121-140.

Beltrán, Vicente (1997): "A alba de Nuno Fernandez Torneol", Revista galega do ensino, 17, pp. 89-109.

Beltrán, Vicente (1998): "Tipos y temas trovadorescos. XV. Johan Soarez Coelho y el ama (de don Denis)", Bulletin of Hispanic Studies, 75, pp. 13-43, <https://doi.org/10.3828/bhs.75.1.13>.

Beltrán, Vicente (ed.) (2000): Jorge Manrique, Poesía, Barcelona, Crítica.

Beltrán, Vicente (2001): "Los Gozos de amor de Juan Rodríguez del Padrón: edición crítica", en Leonardo Funes y José Luis Moure (eds.), Studia in honorem Germán Orduna, Alcalá de Henares, Universidad de Alcalá, pp. 91-110.

Beltrán, Vicente (2009): Edad Media: Lírica y cancioneros, Madrid, Visor.

Beltrán de Heredia, Vicente (1970): Cartulario de la Universidad de Salamanca, Salamanca, Universidad de Salamanca.

Bertolucci Pizzorusso, Valeria (1963): Le poesie di Martin Soares, Bologna, Libreria Antiquaria Palmaverde.

Brea, Mercedes (1999): "Las cantigas de romería de los juglares gallegos", en S. Fortuno Llorens y T. Martínez Romero (eds.), Actes del VII Congrès de l'Associació Hispánica de Literatura Medieval, I, Castellón de la Plana, Universitat Jaume I, pp. 381-396.

Burgazzi, Riccardo (2015): "La romaría cantata da Johan Servando", Carte Romanze, 3, 1, pp. 9-43.

Cabré, Miriam (2011): "Who are Cerveri's worst enemies?", Glossator, 4, pp. 59-72.

Casas Rigall, Juan (1995): Agudeza y retórica en la poesía amorosa de cancionero, Santiago de Compostela, Universidade de Santiago de Compostela.

Casas Rigall, Juan (2009): "En el texto de Macías: edición crítica de «Cativo de miña tristura»", Zeitschrift für romanische Philologie, 125.1, pp. 106-127, <https://doi.org/10.1515/ zrph.2009.006>.

Cohen, Rip (2003): 500 Cantigas d' Amigo, Porto, Campo das Letras.

Cohen, Rip (2013): "Internal Rhyme and the History of Strophic Song", en Virtual Center for the Study of Galician-Portuguese Lyric, vol. 1, <https://blogs.commons.georgetown.edu/cantigas/ files/2014/12/Cohen-Internal-Rhyme-Article.pdf>.

Correia, Angela (1993): "Sobre a especificidade da cantiga de romaria", Revista da Biblioteca Nacional, 8, pp. 7-22.

Cortines, Jacobo (ed.) (1984): Petrarca, Cancionero, Madrid, Cátedra.

Cunha, Celso Ferreira da (1982): Estudos de versificação portuguesa, Paris, Calouste Gulbenkian.

Deyermond, Alan (1982): "Baena, Santillana, Resende and the Silent Century of Portuguese Court Poetry", Bulletin of Hispanics Studies, 59, pp. 265-283, <https://doi.org/10.3828/bhs.59.3.198>.

Dutton, Brian (1990-1991): El Cancionero del siglo XV (c. 1360-1520), Salamanca, Universidad de Salamanca, 7 vols.

Dutton, Brian y González Cuenca, Joaquín (1993): Cancionero de Juan Alfonso de Baena, Madrid, Visor.

Farinelli. Arturo (1929): Italia e Spagna, Torino, Fratelli Bocca-Editori, 2 vols.

Ferreiro, Manuel (dir.) (2018-): Universo Cantigas. Edición crítica da poesía medieval galegoportuguesa, A Coruña, Universidade da Coruña, <http://universocantigas.gal $>$.

Fregonese, Roberta (2007): Joham Vaasquiz de Talaveyra. Poesie e tenzoni. Edizione critica, introduzione, note e glossario, Milano, Edizioni Spolia.

Fucilla, Joseph G. (1953): Estudios sobre el petrarquismo en España, Madrid, CSIC.

Gaibrois de Ballesteros, Mercedes (1922): Sancho IV de Castilla, vol. I, Madrid, Tipografía de la Revista de Archivos, Bibliotecas y Museos. 
Gallagher, Patrick (ed.) (1968): The life and works of Garci Sánchez de Badajoz, London, Tamesis Books.

Gilderman, Martin S. (1982): "Juan Rodríguez del Padrón: profeta mártir del amor cortés", en Eugenio de Bustos Tovar (ed.), Actas del IV Congreso Internacional de Hispanistas, Salamanca, Universidad de Salamanca, pp. 659-664.

Gonçalves, Elsa (1986): "Presupostos históricos e geográficos à crítica textual no âmbito da lírica medieval galego-portuguesa: (1) Quel da Ribeira; (2) A Romaria de San Servando", en Critique textuelle portugaise. Actes du Colloque (Paris, octobre 1981), Paris, Fondation Calouste Gulbenkian, pp. 41-53.

Gonçalves, Elsa (1993): "Atehudas ata a finda", en Mercedes Brea (coord.), O cantar dos trobadores. Actas do Congreso (Santiago de Compostela, 26 e 29 abril 1993), Santiago de Compostela, Xunta de Galicia, pp. 167-186.

Haywood, Louise (2016): "Juan de Torre's Poetics of Vision: Oiosqueyanovesque", Medievalia, 19.1, pp. 111-145, <https://doi.org/10.5565/rev/medievalia.423>.

Indini, Maria Luisa (1978): Bernal de Bonaval. Poesie, Bari, Adriatica Editrice.

Lapesa, Rafael (1953-1954): "La lengua de la poesía lírica desde Macías hasta Villasandino", Romance Philology, 7, pp. 51-59.

Lapesa, Rafael (1982): De la Edad Media a nuestros días, Madrid, Gredos.

Le Gentil, Pierre (1949): La Poésie lyrique espagnole et portugaise à la fin du Moyen Âge, I, Les Thèmes et les genres, Rennes, Philon.

Lopes, Graça Videira y Manuel Pedro Ferreira (dirs.) (2011-): Cantigas Medievais Galego Portuguesas [base de datos online], Lisboa, Instituto de Estudos Medievais, FCSH/NOVA, $<$ http://cantigas.fcsh.unl.pt>.

Lorenzo Gradín, Pilar (1997a): "Voces de mujer y mujeres con voz en las tradiciones hispánicas medievales", en Iris M. Zavala (coord.), Breve historia feminista de la literatura española (en lengua castellana). 4. La literatura escrita por mujer: desde la Edad Media hasta el siglo XVIII, Barcelona, San Juan de Puerto Rico, Anthropos, Universidad de Puerto Rico, pp. 3-82.

Lorenzo Gradín, Pilar (1997b): "El dobre gallego-portugués o la estética de la simetría", Vox Romanica, 56, pp. 212-241.

Mosquera Novoa, Lucía (2015): Juan de Torres: edición y estudio de su poesía, tesis doctoral, Universidade da Coruña, <http://hdl.handle.net/2183/15935>.

Mosquera Novoa, Lucía (ed.) (2016): La poesía de Juan de Torres, Alessandria, Edizioni dell' Orso.

Oliveira, António Resende de (1994): Depois do espectáculo trovadoresco. A estructura dos cancioneiros peninsulares e as recolhas dos séculos XIII e XIV, Lisboa, Edições Colibri.

Pérez Bosch, Estela (2009): Los valencianos del "Cancionero General": estudio de sus poesías, Valencia, Universitat de València.

Pérez Priego, Miguel Ángel (2013): Literatura Española Medieval (el siglo XV), Madrid, Ramón Areces, UNED.

Pla Colomer, Francisco (2016): "Aproximación lingüística al Cancionero de Baena en su contexto poético", Revista Electrónica del Lenguaje, 3, pp. 1-15, <https://www.revistaelectronicalenguaje. com/wp-content/uploads/2016/10/Vol-03-02-Francisco-P.-Pla-Colomer.pdf>.

Proia, Isabella (2015): "A proposito della koinè galego-castigliana. Alcune considerazioni sulla tradizione testuale dell'Arcediano de Toro", Critica del testo, XVIII/3, pp. 137-154.

Reali, Erilde (1964): Le "cantigas" di Juyão Bolseyro, Napoli, Pubblicazioni della sezione romanza dell' Istituto Universitario Orientale.

Recio, Roxana (ed.) (2007): Estudios sobre el nuevo petrarquismo: un aspecto fundamental de las relaciones hispano-italianas, Revista de poética medieval, 18, número monográfico.

Richard, Javier A. (2011): Fernando III: cruzado y santo, Cádiz, Absalon Ediciones.

Rico, Francisco (1976): "Cuatro palabras sobre Petrarca en España (siglos XV y XVI)", en Convegno Internazionale Francesco Petrarca, Roma, Accademia Nazonale dei Lincei, pp. 49-58. 
Rico, Francisco (1978): "De Garcilaso y otros petrarquismos", Revue de Littérature Comparée, 52, pp. 325-338.

Rico, Francisco (1987): "A fianco di Garcilaso: poesia italiana e poesia spagnola nel primo cinquecento", Studi Petrarcheschi, 4, pp. 229-236.

Riquer, Isabel de (2015): "Women and Feigned Pilgrimages", en Carlos Andrés González-Paz (ed.) Women and Pilgrimage in Medieval Galicia, Surrey (UK), Burlington (USA), Ashgate, pp. 155-167.

Rodado Ruiz, Ana M." (2000a): "Tristura conmigo va": fundamentos de amor cortés, Cuenca, Universidad de Castilla-La Mancha.

Rodado Ruiz, Ana M.. (ed.) (2000b): Pedro de Cartagena, Poesías, Cuenca, Universidad de Castilla-La Mancha.

Rodríguez-San Pedro Bezares, Luis Enrique (2002-2019): Historia de la Universidad de Salamanca, Salamanca, Universidad de Salamanca, 6 vols.

Rodríguez Lapa, Manuel (1965): Cantigas d' escarnho e de mal dizer dos cancioneiros medievais galego-portugueses, Vigo, Galaxia.

Ron Fernández, Xabier (2005): "Carolina Michaëlis e os trovadores representados no Cancioneiro da Ajuda", en Carolina Michaëlis e o Cancioneiro da Ajuda, hoxe, Santiago de Compostela, Xunta de Galicia, pp. 121-188.

Ron Fernández, Xabier (2015): A fenomenoloxía do don na lírica románica das primeiras xeracións, tesis doctoral (inédita), Universidade de Santiago de Compostela.

Rovira, José Carlos (1990): Humanistas y poetas en la corte napolitana de Alfonso el Magnánimo, Alicante, Instituto Juan Gil-Albert.

Sáez Durán, Juan (2019): "Elaboración de una lengua poética y code-mixing: en torno a la configuración lingüística del corpus gallego-castellano", en Isabella Tomasetti (ed.), Avatares y perspectivas del medievalismo ibérico, vol. II, San Millán de la Cogolla, Cilengua, pp. 1205-1215.

Sansone, Giuseppe E. (1974): "Temi e técnica delle cantigas d' amor di Johan Garcia de Guilhade", en Saggi Iberici, Bari, Adriatica Editrice, pp. 9-38.

Souto Cabo, José António (1988): "Aproximaçom ao motivo dos olhos nas cantigas de amor e amigo", Agália. Revista da Associaçom Galega da Língua, 16, pp. 401-420.

Souto Cabo, José António (2012): "En Santiago, seend' albergado en mia pousada. Nótulas trovadorescas compostelanas", Verba, 39, pp. 273-298.

Souto Cabo, José António (2018): "Martin Codax e o fenómeno jogralesco na Galiza sul-ocidental", en Alexandre Rodríguez Guerra y Xosé Bieito Arias Freixedo (coords.), The Vincel Parchment and Martin Codax / O Pergamiño Vindel e Martin Codax. The Golden Age of Medieval Poetry / O esplendor da poesía galega medieval, Amsterdam, Philadelphia, Jonh Benjamins Publishing Company, pp. 83-101.

Tavani, Guiseppe (1967): Repertorio métrico della lirica galego-portoghese, Roma, Edizioni dell' Ateneo.

Tavani, Giuseppe (1983): "L'ultimo periodo della lirica galego-portoghese: archiviazione di un'esperienza poetica", Revista da Biblioteca Nacional, III, 1-2, pp. 9-17.

Toro Pascua, María Isabel (2009): "Gracián y los poetas de Cancionero: del Arte de ingenio (1642) a la Agudeza y Arte de ingenio (1648)", Conceptos. Revista de investigación graciana, 6, pp. 67-85.

Toro Pascua, María Isabel y Vallín, Gema (2005): "Hibridación y creación de una lengua poética: el corpus gallego-castellano", Revista de poética medieval, 15, pp. 93-106.

Toro Pascua, María Isabel y Vallín, Gema (2006): "Lírica culta, lírica popular: intercambios ("Ver y desear': un villancico popular de origen trovadoresco)", en Pedro M. Cátedra (ed.), La literatura popular impresa en España y en la América Colonial: formas \& temas, géneros, funciones, difusión, historia y teoría, Salamanca, SEMYR-Instituto de Historia del Libro y de la Lectura, pp. 169-189.

Vallín, Gema (1996): Las cantigas de Pay Soarez de Taveirós. Estudio histórico y edición, Alcalá de Henares, Universidad de Alcalá. 
Vasconcelos, Carolina Michaëlis de (1990): Cancioneiro da Ajuda, vols. I. e II, Lisboa, Imprensa Nacional, Casa da Moeda [reimpressão da edição de Halle: Max Niemeyer, 1904, acrescentada de um prefácio de Ivo Castro e do glossário das cantigas, Revista Lusitana, XXIII].

Víñez, Antonia (1996): "Documentación de trovadores", en Carlos Alvar y José Manuel Lucía Mejías (coords.), La literatura en la época de Sancho IV (Actas del Congreso Internacional "La literatura en la época de Sancho IV”, Alcalá de Henares, 21-24 de febrero de 1994), Alcalá de Henares, Universidad de Alcalá, pp. 531-542.

Whetnall, Jane (2006): "Las transformaciones de Petrarca en cuatro poetas de cancionero: Santillana, Carvajales, Cartagena y Florencia Pinar", Cancionero General, 4, pp. 81-108.

Zinato, Andrea (1996): Macías. L'esperienza poetica galego-castigliana, Venezia, Cafoscarina.

Fecha de recepción: 14 de abril de 2020

Fecha de aceptación: 2 de julio de 2020 